\title{
The Study on Generating Mechanism of Employee Involvement in Lean Production: an Application of the Theory of Planned Behavior Xizhen Gao ${ }^{1, a}$, Yanjiao Han ${ }^{1, b}$ and Chaochao Liü, \\ ${ }^{1}$ School of Management, Tianjin University of Technology, Tianjin 300384, China; \\ ${ }^{2}$ School of Management \& Economics, Tianjin University, Tianjin 300072, China. \\ agaoxizhen@163.com, hanyanjiaoTJ@163.com, liuchao1988aaa@163.com.
}

Keywords: Lean production, Employee involvement, Behavior mechanism, Theory of planned behavior.

\begin{abstract}
The effectiveness of employee involvement is very important to lean production performance. In order to explain mechanism of employee involved in lean production, to improve the effectiveness of employee involvement, a model of employee involvement behavior mechanism is constructed, based on the theory of planned behavior and the characteristic analysis of employee involvement behavior. the sample data collecting by questionnaire and hypothesis testing by the structural equation model, then we got some conclusions:(1) injunctive norm directly impact on employee involvement behavior and the mediation role of intention between injunctive norm and involvement behavior is non-significant; (2) participation attitude and moral norm can influence the involvement behavior through the mediation role of intention, and the instrumental attitude has the most significant relationship; (3) descriptive norm and perceived behavior control either through intention have the intermediary effect on involvement behavior, also can directly affect the involvement behavior. This research results have a certain guiding significance for enterprise to improve employee effectiveness in lean production.
\end{abstract}

\section{Introduction}

Lean production is a strategic choice to improve the market competitiveness due to its operating low-cost and high-efficiency [1]. Lean production focus on employee involvement, because it can not only promote the implementation of new production methods, but also upgrade the staff's quality and ability. However, employees maybe resist lean production since there are innovations, work content change, uncertainty, more challenges etc. during the implementation of lean production system. Therefore, it is very important studying how to incentive employees to actively participate in lean manufacturing.

This study attempts to use TPB to explain the behavior motivation of employee involving lean production, and verify the intrinsic relationship between employee involvement behavior influencing factors by structural equation model, further more to reveal generating mechanism of employee involvement behavior. Accordingly, some incentive suggestions will be put forward to encourage employees actively involvement and improve performance of lean production.

\section{Theoretical background---Theory of Planned Behavior}

Theory of Planned Behavior (TPB) is put forward by Icek Ajzen $(1988,1991)$. It argued human behavior was control by behavioral attitude, subjective norm, and perceived behavioral control [2,3], it is deliberation result. TPB provided an analytical framework to explain and predict individual behavior through incorporating the above factors [4]. According to TPB, attitude is individual impact factors of the behavior decision; Subjective norm indicated the expectation coming from team and others; Perceived behavioral control indicated the personal perception about the factors on behavior. The three factors were interrelated with each other and effect on behavioral intention together. Behavioral intention was the tendency of individual special behavior. It had a direct impact on the involvement behavior with the perceived behavioral control. The relationship is shown in 
Fig.1.

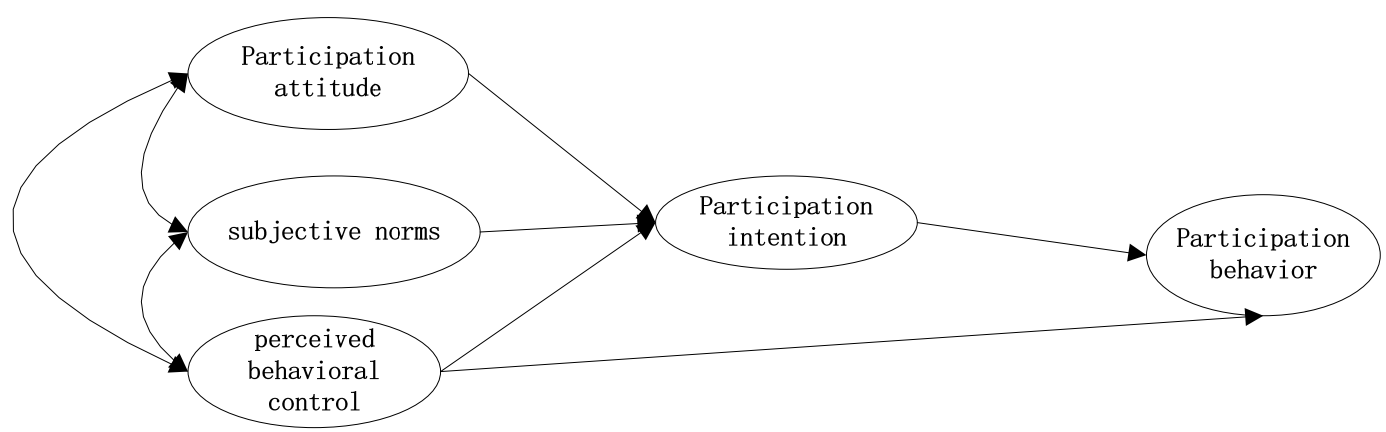

Fig. 1 Theory of Planned Behavior Chart

\section{Hypotheses}

According TPB, this study makes the following hypotheses:

H1a: Emotional attitude has a direct positive impact on employee involvement intention;

$\mathrm{H} 1 \mathrm{~b}$ : Instrumental attitude has a direct positive impact on employee involvement intention.

H2a: Moral norm has a direct positive impact on employee participation intention;

$\mathrm{H} 2 \mathrm{~b}$ : Descriptive norm has a direct positive impact on employee participation intention;

$\mathrm{H} 2 \mathrm{c}$ : Injunctive norm has a direct positive impact on employee participation intention.

H3a: Self-efficacy has a direct positive impact on employee participation intention;

$\mathrm{H} 3 \mathrm{~b}$ : Perceived authorization has a direct positive impact on employee participation intention.

H4: Employee participation has a direct positive impact on employee participation behavior.

H5a: Emotional attitude has a direct positive impact on employee participation behavior;

H5b: Instrumental attitude has a direct positive impact on employee participation behavior.

H6a: Moral norm has a direct positive impact on employee participation behavior;

H6b: Descriptive norm has a direct positive impact on employee participation behavior;

H6c: Injunctive norm has a direct positive impact on employee participation behavior.

H7a: Self-efficacy has a direct positive impact on employee participation behavior;

$\mathrm{H} 7 \mathrm{~b}$ : Perceived authorization has a direct positive impact on employee participation behavior.

\section{Research Methods}

\subsection{Questionnaire Design and Research Methods selection}

The mature questionnaire was modified according to Chinese context to ensure the reliability and validity. Participation behavior uses the questionnaire with three items, which Coyle-Shapiro et al. had used to research employee involvement behavior in the Total Quality Management [5]. In order to ensure the quality of questionnaire, all the items are measured on a 5-point Likert scale from "totally disagreement" to "fully agreement". This study uses structural equation model to verify assumptions [6].

\subsection{Sample selection and data collection}

Two companies (including three factories) were selected to distribute questionnaire. The total number of questionnaires is 300,12 copies are invalid and 288 are valid, so the effective rate is $96 \%$. Spss 18 software proved the questionnaire has better reliability and validity.

\section{Hypothesis testing}

\subsection{Initial inspection}

The survey data are carried out hypothesis testing, with Amos 21 guidance, the non-significant paths are excluded. The path model of latent variables is shown in Fig.2. 


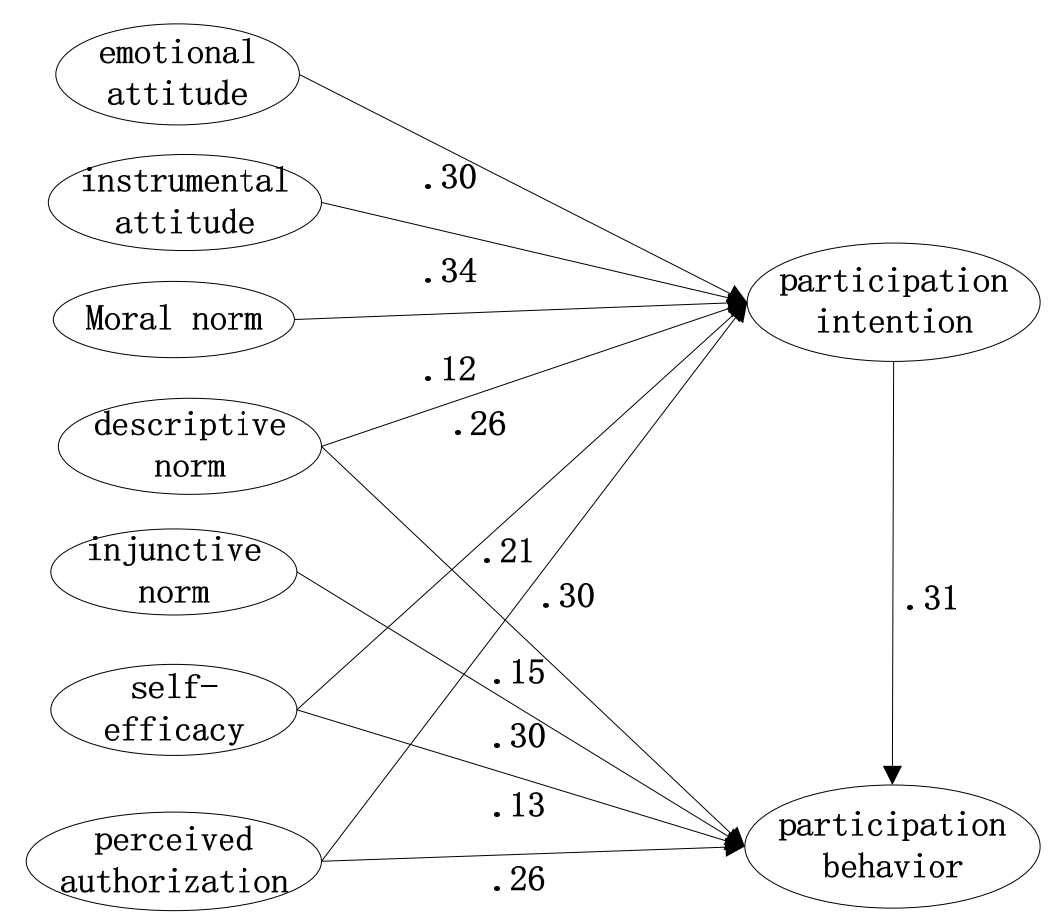

\subsection{Verification of Modified Model}

Fig.2 Structural equation path mode of latent variables

To form normative generating mechanism model of participation behavior, the non-significant paths in initial assumptions are rejected. Modified path model of latent variables is shown in Fig.3.

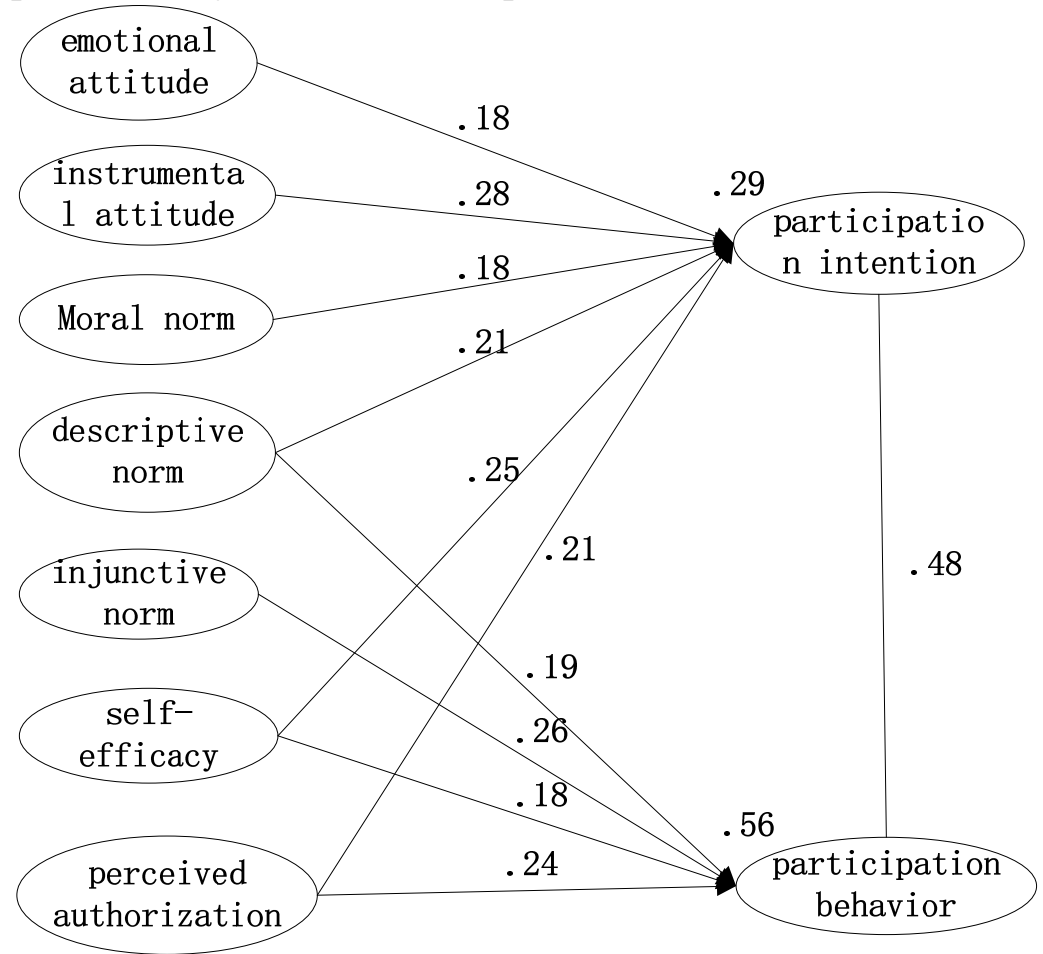

Fig.3 Modified structural equation path model of latent variables

\section{Summary}

The study decomposes the behavior motivation of TPB, based on a review of references on participation behavior. Combined with employee participation behavior characteristics, moral norm and perceived authorization are introduced to build conceptual model of generating mechanism of employee involvement in lean production. Secondly, theory of TPB has been tested and modified with structural equation model .Three main conclusions are received. 
1. Injunctive norm has a direct impact on participation behavior, Without going through the intermediary role of participation intention.

2. Emotional attitude, instrumental attitude and moral norm all have a effect on participation behavior through participation intention, and the path relationship of the instrumental attitude is the most significant .

3.The relationship between descriptive norm, self-efficacy, perceived authorization and participation behavior is partly through participation intention, which indicates unexplained variation is existing.

\section{References}

[1] Anand G, Ward P T, Tatikonda M V, et al. Dynamic capabilities through continuous improvement infrastructure. Journal of Operations Management . Vol.27 (2009) No.6,p.444-461.

[2] Ajzen I.The theory of planned behavior.Organizational behavior and human decision processes.Vol.50 (1991) No.2,p. 179-211.

[3] Ajzen I, Madden T J. Prediction of goal-directed behavior: Attitudes, intentions, and perceived behavioral control. Journal of experimental social psychology, Vol.22 (1986) No.5,p. 453-474.

[4] Sim K L, Rogers J W. Implementing lean production systems: barriers to change. Management Research News.Vol.32 (2008) No.1,p. 37-49.

[5] Coyle-Shapiro J A M, Morrow P C. The role of individual differences in employee adoption of TQM orientation .Journal of Vocational Behavior.Vol.62 (2003) No.2,p. 320-340.

[6] Ming-long Wu. Structural equation model---Operation and application of AMOS. Chongqing University Press.2009,p.38-59. 